\title{
Biodegradation of 4-chlorophenol in an airlift inner loop bioreactor with mixed consortium: effect of HRT, loading rate and biogenic substrate
}

\author{
Bhishma P. Patel ${ }^{1} \cdot$ Arvind Kumar $^{1}$
}

Received: 30 September 2015/Accepted: 25 May 2016/Published online: 2 June 2016

(c) The Author(s) 2016. This article is published with open access at Springerlink.com

\begin{abstract}
In the present work, removal of 4-chlorophenol (4-CP) by the mixed microbial consortium was evaluated in an airlift inner loop bioreactor. During the study, the effect of various reactor parameters such as hydraulic retention time (HRT), biogenetic substrate concentration, loading rate, and initial substrate concentration on the removal efficiency of 4-CP was investigated. Bioreactor showed a maximum removal rate of $16.59 \mathrm{mg} / \mathrm{L} / \mathrm{h}$ at the optimum conditions of $24 \mathrm{~h}$ HRT, $400 \mathrm{mg} / \mathrm{L}$ initial $4-\mathrm{CP}$, and $0.2 \mathrm{~g} / \mathrm{L}$ peptone. The optimum HRT found was $24 \mathrm{~h}$ after that the washout occured, and the degradation efficiency almost dropped to $50 \%$ at $18 \mathrm{~h}$ HRT. Effect of peptone showed that lower concentration of peptone improves 4-CP removal efficiency of the bioreactor. Also, the mixed consortium had utilized 4-CP as a carbon source, as evidenced by the increasing biomass concentration with 4-CP at constant peptone concentration. The presence of 5-chloro 2-hydroxymuconic semialdehyde in the reactor infers that the mixed consortium has followed the metacleavage pathway for 4-CP degradation.
\end{abstract}

Keywords 4-chlorophenol - Airlift reactor .

Biodegradation - Wastewater - Biogenic substrate

Bhishma P. Patel

bhishmaptl@gmail.com

Arvind Kumar

arvindkumar@nitrkl.ac.in

1 Environmental Pollution Abatement Lab, Chemical Engineering Department, National Institute of Technology, Rourkela, Odisha 769008, India

\section{Introduction}

With heavy industrialization and urbanization, activities polluting the environment and concomitantly sabotaging the inherent ecosystems have enormously increased. Chlorophenols have been classified as priority pollutants by the US Environmental Protection Agency (ATSDR 2015). They are primarily found in the industrial effluent from pulp and paper, leather tanning, biocide, dyes, herbicide and chlorination of drinking and waste water (Olaniran and Igbinosa 2011; Field and Sierra-Alvarez 2008; Wang et al. 2014). Chlorophenols are persistent and bio-accumulative in nature due to its physicochemical properties that cause detrimental effects on the environment. Chlorophenol compounds have been demonstrated to have mutagenicity, carcinogenicity, immunogenicity, and may cause fatalities (IARC 1986; Daniel et al. 2001). Conventional methods such as adsorption, chemical oxidation, photo-degradation and solvent extraction have limitations due to their high cost of implementation, production of toxic by-products and low energy efficiency (Herrera et al. 2008; Durruty et al. 2011). These treatments transform the toxic compounds from one phase to another. On contrary, biological treatment is a potential substitute with promising removal efficiency and complete mineralization of the chlorophenols. It is eco-friendly and energy efficient treatment with assuring future (Field and Sierra-Alvarez 2008; Olaniran and Igbinosa 2011; Basak et al. 2013, 2014; Chakraborty et al. 2013).

There are several reports on various microorganisms that have been identified for utilizing chlorophenols as a carbon and energy source such as Pseudomonas aeruginosa, Pseudomonas putida, Comamonas testosteroni, Ralstonia eutropha, Bacillus subtilis, Arthrobacter chlorophenolicus, Burkholderia sp., and Kocuria

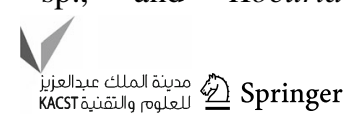


rhizophila. (El-Sayed et al. 2009; Arora and Bae 2014; Field and Sierra-Alvarez 2008; Hollender et al. 1997; Monsalvo et al. 2012; Patel and Kumar 2015, 2016). Biodegradation of chlorophenols in different bioreactor system under aerobic and anaerobic conditions has been reported. Attention has been given to study and modify the different bioreactors such as packed bedreactor, fluidized bed reactor, upflow anaerobic sludge blanket, combined anaerobic and aerobic treatment and membrane reactor to enhance the performance of wastewater treatment containing lower to higher chlorophenols (Quan et al. 2003; Galíndez-Mayer et al. 2008; Gomez-De Jesus et al. 2009; Visvanathan et al. 2005; Atuanya and Chakrabarti 2004). Aerobic biodegradation is usually preferred for lower chlorophenols such as mono and di-chlorophenol and sometimes tri-chlorophenols. While, for the treatment of higher chlorophenols such as tri, tetra, and pentachlorophenol, an anaerobic biodegradation is more effective (Poggi-Varaldo et al. 2012).

Wastewater treatment plant commonly contains the mixture of different recalcitrant synthetic organic compounds (SOC) along with biogenic substrates. The common treatment plants are not able to treat recalcitrant SOC effectively and generally passes through without complete treatment (Hu et al. 2005). The treatment of recalcitrant compounds can be improved by process optimization. These require the understanding of biomass acclimation, interaction between biogenic substrate and recalcitrant compounds, and reactor operating conditions for SOC treatment. Different factors such as hydraulic retention time, loading rate and the presence of other secondary carbon and nitrogen source have to be considered and optimized for better performance and efficiency of the bioreactors.

Airlift reactors (ALR) are simple in design with no moving parts or agitator, thus economical. In ALR, pressurized gas is used for internal mixing and aeration. It has low shear stress on microbial cells which will be an advantage for shear sensitive cells. In packed bed reactor where mass and oxygen transfer limitation and clogging of packing bed occur, these problems can be avoided in ALR (Zilouei et al. 2006; Quan et al. 2003). There are several reports on biodegradation of chlorophenols and other toxic compounds using ALR. Quan et al. (2003, 2004) reported the removal of phenol and 2,4-dichlorophenol in the airlift honeycomb-like ceramic reactor (Quan et al. 2003, 2004). They have used ceramic honeycomb-like structure placed inside the riser for immobilization of pure culture Achromobacter sp. A packed bed bioreactor equipped with the net draft tube riser (PB-ALR) for liquid circulation and oxygenation was constructed for the removal of 2,4,6trichlorophenol (Gomez-De Jesus et al. 2009). In the present study, simple airlift bioreactor without any immobilization of microorganism was used for removal of 4-chlorophenol. The absence of agitator for mixing and any carrier for immobilization of microorganism makes the bioreactor simple with ease in operation and economical.

The present study focussed on the continuous biodegradation of 4-chlorophenol in an airlift inner loop bioreactor using the mixed microbial consortium. During the continuous operation, the effect of different parameters such as hydraulic retention time, loading rate, biogenic substrate concentration and initial substrate concentration on removal efficiency of ALR was studied. The different metabolites present in the effluent were detected to analyze the biodegradation pathway followed by the mixed consortium.

\section{Materials and methods}

\section{Chemicals and reagents}

Loba chemie, India supplied analytical grade 4-CP (purity $98 \%$ ). The stock solution of 4-CP was prepared in $0.02 \mathrm{M}$ $\mathrm{NaOH}$ and $\mathrm{pH}$ was adjusted to $7.4 \pm 0.2$ by $1 \mathrm{M}$ orthophosphoric acid. All other inorganic chemicals used in the experiments were of analytical grade and obtained from Merck, India. HPLC grade reagents were obtained from Hi-media, India for HPLC analysis.

\section{Microorganisms}

The mixed microbial consortium used in the study was previously isolated from the sludge, and soil samples collected from the dye industries effluent treatment plant, Gujarat, India. For enrichment and acclimatization, $10 \mathrm{gm}$ of sludge and soil was added to $100 \mathrm{~mL}$ of mineral salt medium (MSM) (composition mentioned elsewhere in the paper) containing peptone $(1-0.1 \mathrm{~g} / \mathrm{L})$ and $2,4-\mathrm{DCP}$ $(20-250 \mathrm{mg} / \mathrm{L})$ and incubated at $30{ }^{\circ} \mathrm{C}$ and $120 \mathrm{rpm}$ in rotary shaker for a period of 6 months. The enriched culture was transferred to fresh MSM at every 15 days with increasing concentration of 2,4-DCP. The mixed consortium resulted after acclimatization period is used in the present study for biodegradation of 4-CP.

\section{Bioreactor medium}

The bioreactor was fed with the MSM containing 2,4-DCP and peptone as a carbon and energy source. The composition of the MSM (modified DSMZ-465) was $(\mathrm{g} / \mathrm{L}): \mathrm{Na}_{2}$ $\mathrm{HPO}_{4} \cdot 2 \mathrm{H}_{2} \mathrm{O} 3.5, \mathrm{KH}_{2} \mathrm{PO}_{4} 1,\left(\mathrm{NH}_{4}\right)_{2} \mathrm{SO}_{4} 0.5, \mathrm{MgCl}_{2} \cdot 6 \mathrm{H}_{2} \mathrm{O}$ $0.1, \mathrm{NaNO}_{3} 0.05$ and $1 \mathrm{~mL}$ of trace element solution having composition of $(\mathrm{g} / \mathrm{L})$ : EDTA $0.5, \mathrm{FeSO}_{4} \cdot 7 \mathrm{H}_{2} \mathrm{O} 0.2$, $\mathrm{CuCl}_{2} \cdot 2 \mathrm{H}_{2} \mathrm{O} \quad 0.001, \quad \mathrm{ZnSO}_{4} \cdot 7 \mathrm{H}_{2} \mathrm{O} \quad 0.01, \quad \mathrm{MnCl}_{2} \cdot 4 \mathrm{H}_{2} \mathrm{O}$ 
0.003, $\mathrm{CoCl}_{2} \cdot 6 \mathrm{H}_{2} \mathrm{O} 0.02, \mathrm{H}_{3} \mathrm{BO}_{3} 0.03, \mathrm{Na}_{2} \mathrm{MoO}_{4} \cdot 2 \mathrm{H}_{2} \mathrm{O}$ 0.003 . The trace elements and $4-\mathrm{CP}$ were added to the medium after autoclaving by filter sterilizing using $0.22 \mu \mathrm{m}$ filters. The $\mathrm{pH}$ of the medium was adjusted to $7.35 \pm 0.1$ using $1 \mathrm{M} \mathrm{H}_{3} \mathrm{PO}_{4}$ and $1 \mathrm{M} \mathrm{NaOH}$. For the bioreactor study, the medium was prepared using the filtered tap water.

\section{Bioreactor}

An airlift inner loop reactor made of Perplex glass was used throughout the experiment (Fig. 1). The outer core has a dimension of $18 \times 60 \mathrm{~cm}$ with a concentrically located inner draft tube of $9.5 \times 35 \mathrm{~cm}$ dimension. The working volume of the reactor is $12 \mathrm{~L}$. The inner draft tube was supported by three metallic clamps. The ceramic disc (90-150 $\mu \mathrm{m}$ pore size) with $9 \mathrm{~cm}$ diameter located below the inner tube was used as air sparger. The medium was fed to the bioreactor using gravitational flow and the flow rate was controlled by the peristaltic pump. Air flow rate used during the study was 4 LPM. The bioreactor was stored in an isolated room with temperature controlling facility $\left(32 \pm 3{ }^{\circ} \mathrm{C}\right)$.

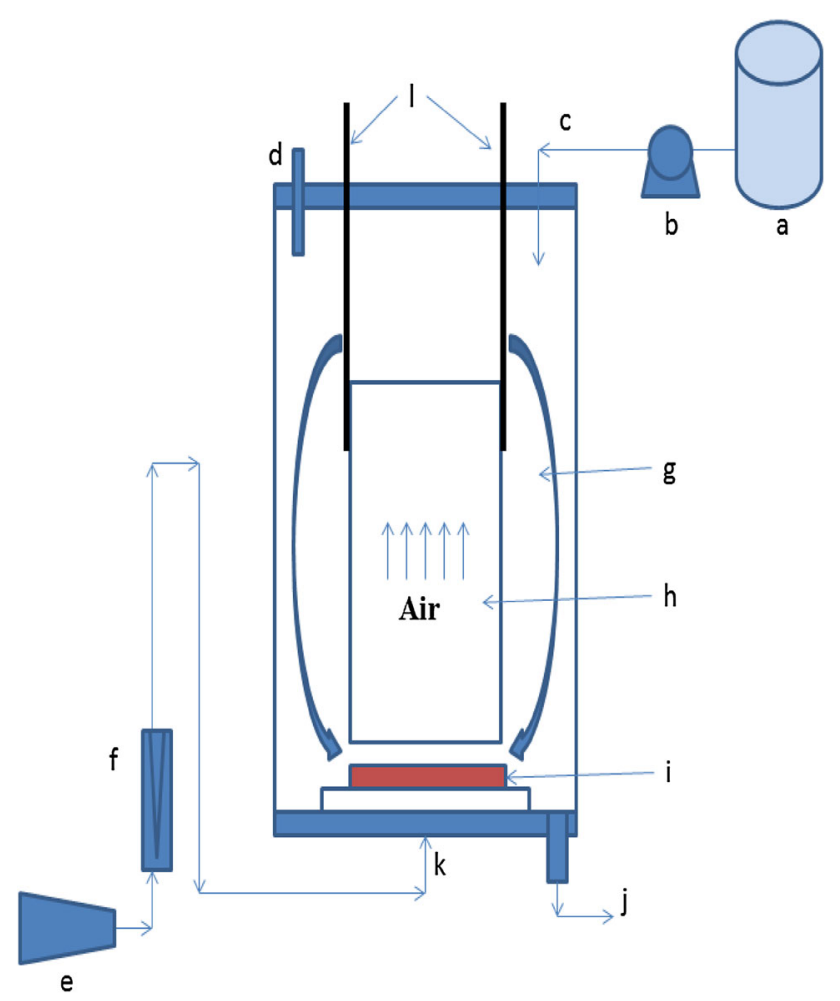

Fig. 1 A schematic view of an airlift inner loop bioreactor. a Feed tank, b peristaltic pump, $\mathbf{c}$ influent, $\mathbf{d}$ air outlet and $\mathrm{pH}$ probe, e air compressor, $\mathbf{f}$ air rotameter, $\mathbf{g}$ downcomer, $\mathbf{h}$ riser, $\mathbf{i}$ air diffuser, $\mathbf{j}$ drainage or effluent, $\mathbf{k}$ air input, $\mathbf{I}$ metal rod supporting inner draft tube
The present investigation focussed on continuous removal of 4-CP, divided into three parts. First, the effect of peptone concentration on removal efficiency of 4-CP was studied. Second, the effect of substrate concentration was studied by gradually increasing it and keeping the other parameters constant. Finally, the effect of HRT on 4-CP removal efficiency was evaluated by gradually decreasing HRT and keeping 4-CP and peptone concentration constant.

\section{Analytical methods}

Biomass concentration was determined by measuring optical density at $600 \mathrm{~nm}$ by UV-Visible spectrophotometer (Shimadzu UV-1800, Japan) (Ziagova and Liakopoulou-Kyriakides 2007). The residual concentration of 4-CP was determined by HPLC system (Jasco, US) coupled with MD-2015 photodiode array detector and 2080 plus isocratic pump. The one $\mathrm{mL}$ sample was centrifuged at $10,000 \mathrm{rpm}$ for $10 \mathrm{~min}$ and supernatant is filtered through $0.22 \mu \mathrm{m}$ filter before analysis. The sample volume taken was $20 \mu \mathrm{L}$. The column used was Agilent TC-C18 $(25 \mathrm{~mm} \times 4.6 \mathrm{~mm})$; the sample was eluted at a flow rate of $0.75 \mathrm{~mL} / \mathrm{min}$ with mobile phase consisting of methanol:water:acetic acid (80:19:1\%); detection wavelength is $280 \mathrm{~nm}$. The 4-CP degradation (\%) was calculated by analyzing the area under the curve (Sahinkaya and Dilek 2007; Karn et al. 2010).

The presence of 5-chloro-2-hydroxymuconicsemialdehyde (5-CHMS) was determined at $380 \mathrm{~nm} \mathrm{UV-Visible}$ spectrophotometer (Shimadzu UV-1800, Japan) (Farrell and Quilty 1999).

Catechol and chlorocatechol were analyzed using the method of Arnow (1937). The samples were centrifuged at $10,000 \mathrm{rpm}$ for $10 \mathrm{~min}$. The supernatant $(0.5 \mathrm{~mL})$ was treated with $0.5 \mathrm{~N} \mathrm{HCl}(0.5 \mathrm{~mL})$. After mixing, $0.5 \mathrm{~mL}$ of nitrite molybdate reagent was added to it resulting in a yellow color. Nitrite molybdate reagent was prepared by dissolving $10 \mathrm{gm}$ of sodium nitrite and $10 \mathrm{gm}$ of sodium molybdate in $100 \mathrm{~mL}$ of distilled water. After mixing, $0.5 \mathrm{~mL}$ of $1 \mathrm{~N} \mathrm{NaOH}$ was added to the mixture resulting in a red color. Finally, the absorbance was measured at $510 \mathrm{~nm}$.

\section{Results and discussion}

The bioreactor was operated for 60 days in a continuous mode during which the effect of different parameters such as HRT, peptone concentration and loading rate on the removal of 4-CP studied. The bioreactor showed an excellent removal efficiency of 4-CP during continuous operation. 
Before the commencement of the continuous operation, the reactor was operated without inoculation to check the abiotic loss of the 4-CP due to evaporation. The bioreactor was filled with MSM containing $40 \mathrm{mg} / \mathrm{L}$ of $4-\mathrm{CP}$ for 1 day, and the air flow was set to 4 LPM. At these conditions, $2-3 \%$ loss due to evaporation by air flow was observed which is negligible as compared to biodegradation.

The bioreactor was filled with $12 \mathrm{~L}$ MSM containing $20 \mathrm{mg} / \mathrm{L}$ of $4 \mathrm{CP}$ and inoculated with $10 \%(\mathrm{v} / \mathrm{v})$ mixed consortium. The bioreactor was operated in the fed-batch mode before the continuous study to acclimatize the biomass. The 4-CP was added to bioreactor periodically to maintain the $20 \mathrm{mg} / \mathrm{L}$ concentration. This acclimatization process was performed for one week and afterwards the continuous operation was started.

\section{Effect of peptone}

The effect of peptone on the removal of 4-CP in ALR was studied throughout the operation at different operating conditions. The bioreactor was started with $1 \mathrm{~g} / \mathrm{L}$ peptone with HRT of $40 \mathrm{~h}$. The effect of peptone in the removal of 4-CP by ALR is presented in Figs. 2 and 3. The bioreactor showed $99 \%$ removal of $20 \mathrm{mg} / \mathrm{L}$ of initial 4-CP present in the influent. However, upon increasing the initial 4-CP concentration to $40 \mathrm{mg} / \mathrm{L}$, the removal efficiency was decreased to around $80 \%$ at $40 \mathrm{~h}$ HRT. At this condition, when HRT was reduced to $30 \mathrm{~h}$, the removal efficiency was decreased to around $50 \%$ and got stabled at $60 \%$ with $1 \mathrm{~g} / \mathrm{L}$ peptone. The reduction in removal efficiency can be explained by two possible reasons. First, at lower HRT, dilution rate was increased which leads to washout and reduction of biomass concentration in the medium. Second, at lower HRT, peptone loading rate was increased leading to decreased level of competent biomass in the medium.

On 15th day of the operation, the peptone concentration was decreased to $0.5 \mathrm{~g} / \mathrm{L}$ in the influent by keeping initial 4-CP concentration at $40 \mathrm{mg} / \mathrm{L}$ and $\mathrm{HRT}$ at $30 \mathrm{~h}$ (Fig. 2). The bioreactor showed an increase in removal efficiency from 60 to $76 \%$ in the presence of low peptone concentration at steady-state condition. On 27th day of the operation, the peptone concentration was further decreased to $0.2 \mathrm{~g} / \mathrm{L}$ in the influent. The HRT was set to $48 \mathrm{~h}$ and $4-\mathrm{CP}$ concentration in the influent was increased gradually at this condition. The bioreactor had shown complete removal of $40 \mathrm{mg} / \mathrm{L}$ 4-CP. The bioreactor performance had greatly increased in the presence of $0.2 \mathrm{~g} / \mathrm{L}$ peptone. Even the bioreactor was able to remove up to $400 \mathrm{mg} / \mathrm{L}$ of $4-\mathrm{CP}$ in the influent with greater than $98 \%$ removal efficiency. It was observed that the biomass concentration in the medium significantly increased at lower peptone concentration. The result indicates that the mixed consortium can utilize the 4-CP as a carbon source with complete mineralization.

The presence of higher concentration of peptone interferes with the degradation of 4-CP by the mixed consortium. However, at low peptone concentration, the removal efficiency increased but some peptone was found to be necessary to maintain the removal efficiency. Same results were obtained in batch studies which also showed that the presence of $0.2 \mathrm{~g} / \mathrm{L}$ of peptone improves the degradation efficiency compared to the absence of peptone. This can be
Fig. 2 The 4-CP removal by ALR and the effect of peptone concentration. The above figure shows the change in biomass concentration in the effluent during the continuous operation
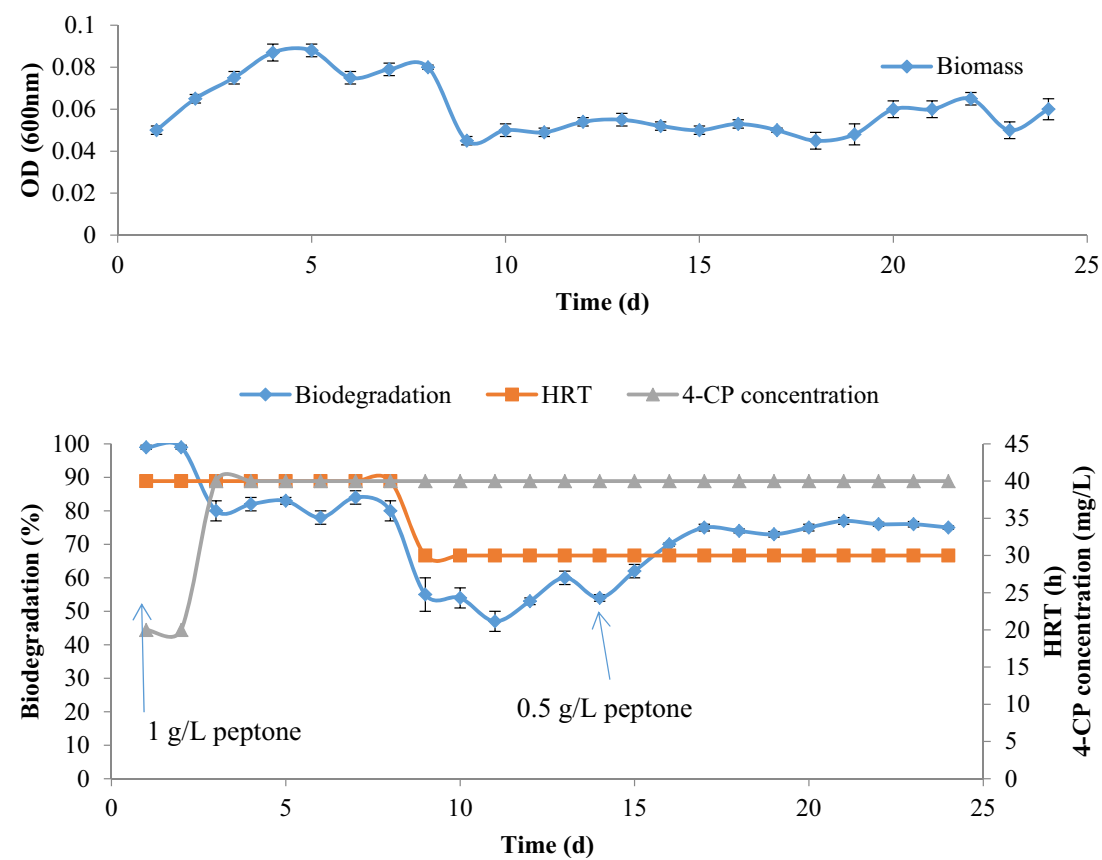
Fig. 3 The 4-CP removal efficiency by ALR in the presence of $0.2 \mathrm{~g} / \mathrm{L}$ peptone and effect of initial substrate concentration and HRT. The above figure shows the change in biomass concentration in the effluent during the continuous operation
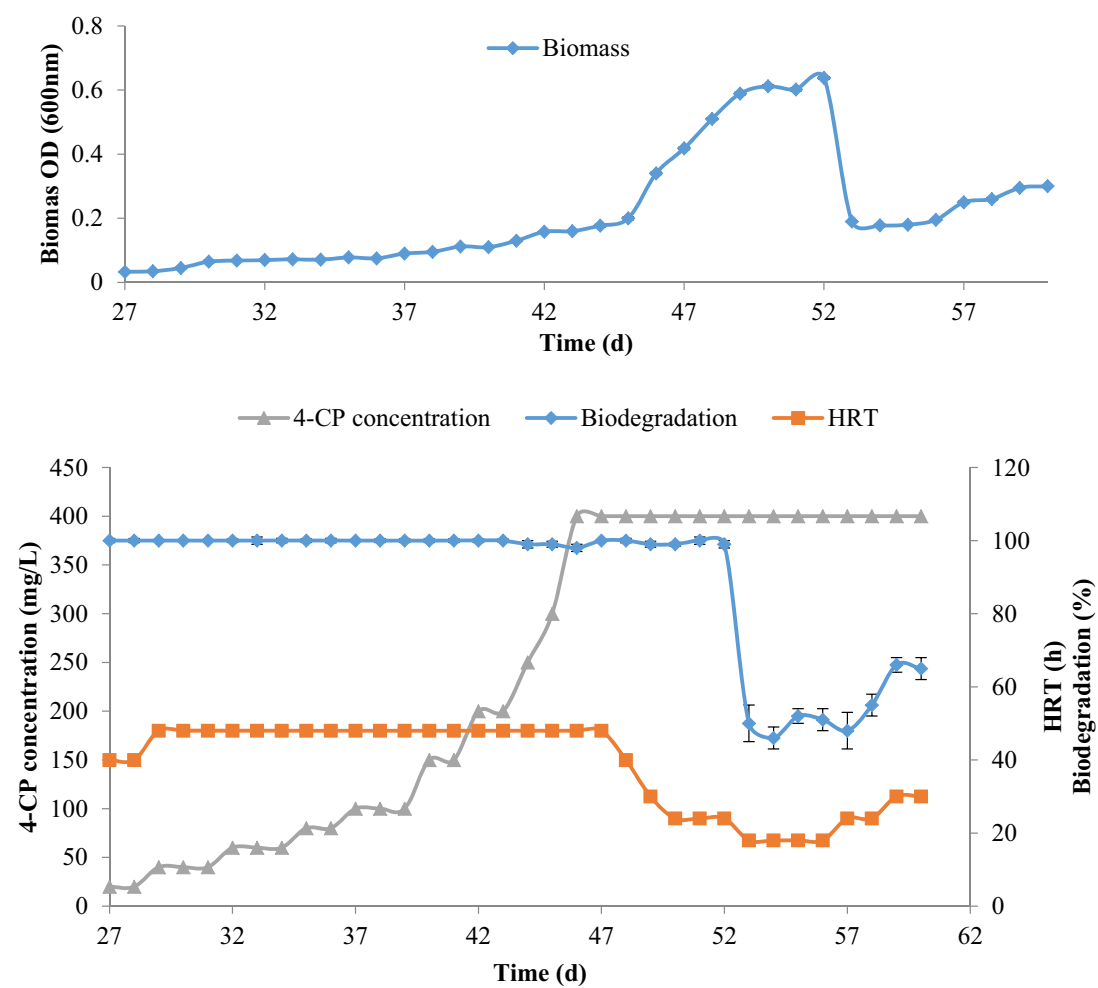

Table 1 Effect of peptone concentration on 4-CP removal by ALR

\begin{tabular}{|c|c|c|c|c|c|c|}
\hline $\begin{array}{l}\text { Time } \\
\text { (day) }\end{array}$ & $\begin{array}{l}\text { Influent concentration } \\
(\mathrm{mg} / \mathrm{L})\end{array}$ & $\begin{array}{l}\mathrm{HRT} \pm 1 \\
\text { (h) }\end{array}$ & $\begin{array}{l}\text { Loading rate } \\
\text { (mg/L/day) }\end{array}$ & $\begin{array}{l}\text { Peptone } \\
\text { (mg/L) }\end{array}$ & $\begin{array}{l}\text { Biodegradation } \\
(\%)\end{array}$ & $\begin{array}{l}\text { Volumetric removal } \\
\text { rate }(\mathrm{mg} / \mathrm{L} / \mathrm{h})\end{array}$ \\
\hline $1-2$ & 20 & 40 & 12 & 1 & 99 & 0.495 \\
\hline $3-8$ & 40 & 40 & 24 & 1 & 82 & 0.82 \\
\hline 9-14 & 40 & 30 & 32 & 1 & 56.5 & 0.753 \\
\hline $15-24$ & 40 & 30 & 32 & 0.5 & 75.8 & 1.01 \\
\hline $29-31$ & 40 & 48 & 20 & 0.2 & 100 & 0.84 \\
\hline $42-43$ & 200 & 48 & 100 & 0.2 & 100 & 4.17 \\
\hline 44 & 250 & 48 & 125 & 0.2 & 99 & 5.2 \\
\hline
\end{tabular}

concluded as the peptone served as a nitrogen source to the mixed consortium as it was used during the acclimatization period. Also, the peptone did not contribute to biomass growth as evidenced by the result that the biomass increases with the decrease in peptone concentration and increase in 4-CP concentration. Thus, it could be concluded that the mixed consortium utilized the 4-CP as a carbon source. Table 1 summarizes the effect of peptone on the removal rate of 4-CP by the mixed consortium.

A specific group of microorganism in the mixed consortium was responsible for the degradation of 4-CP. Sahinkaya and Dilek (2006) studied the effect of peptone on the degradation of 4-CP in sequencing batch reactor using a mixed microbial consortium and reported that competent biomass (specialist) is responsible for 4-CP degradation and so the specific degradation rate of 4-CP increases with decreasing peptone concentration as the fraction of competent biomass increases in the mixed consortium (Sahinkaya and Dilek 2006). There are several reports on the degradation of chlorophenols in the presence of other carbon and nitrogen source such as glucose, dextrose, peptone, and yeast extract. The presence of secondary carbon and nitrogen source witnessed an increase in the degradation of chlorophenols (Sahinkaya and Dilek 2006; Murialdo et al. 2003; Shen et al. 2005; Kim et al. 2002; Wang and Loh 1999). However, there are others reports that publicized the opposing outcomes that sometimes the degradation of higher chlorophenols were inhibited (Durruty et al. 2011; Alexander 1999). Shen et al. (2005) had described the beneficial nature of the presence 
of a suitable quantity of microbial easily degradable substrate for stimulating the process of dechlorination and degradation of chlorophenols (Shen et al. 2005).

\section{Effect of substrate concentration}

Effect of initial 4-CP concentration on the removal efficiency of bioreactor was studied by keeping the HRT $(48 \pm 1 \mathrm{~h})$ and peptone concentration $(0.2 \mathrm{~g} / \mathrm{L})$ constant and gradually increasing 4-CP concentration. The bioreactor showed greater than $99 \%$ removal efficiency when the initial 4-CP concentration was increased from 20 to $400 \mathrm{mg} / \mathrm{L}$. The effect of initial substrate concentration on biodegradation is shown in Fig. 3 (Day 27-47). After $150 \mathrm{mg} / \mathrm{L}$, the 4-CP concentration was increased at a fast rate $(150-400 \mathrm{mg} / \mathrm{L})$ to check the bioreactor stability for shock loads. The bioreactor has shown great stability and removal efficiency even during the shock loads. At lower concentration of 4-CP, complete mineralization was observed with no traces of the intermediate compounds. However, at higher concentration (above $250 \mathrm{mg} / \mathrm{L}$ ), the trace amount of 5-chloro 2-hydroxymuconic semialdehyde (5-CHMS) has been observed. The 5-CHMS $\left(\lambda_{\max }=380 \mathrm{~nm}\right)$ is the meta-cleavage product of the 4-chlorocatechol that gives a characteristic yellow color in the medium. The bioreactor medium was turned to light yellow color when 4-CP concentration was increased to $400 \mathrm{mg} / \mathrm{L}$ due to the accumulation of 5-CHMS. Also, the biomass concentration in the medium was observed to increase with increasing 4-CP concentration. These results indicate that the microorganisms were able to utilize the 4-CP as a sole carbon source.

\section{Effect of HRT}

Effect of HRT on the removal of 4-CP by ALR has been studied from days 47 to 60 . The peptone and initial 4-CP concentration was kept constant at 0.2 and $400 \mathrm{~g} / \mathrm{L}$, respectively. The change in the biodegradation of 4-CP at different HRT is shown in Fig. 3. When the HRT was gradually decreased from 48 to $24 \mathrm{~h}$, no abrupt change in the removal efficiency has been observed. The bioreactor showed greater than $99 \%$ removal of 4-CP at $24 \mathrm{~h}$ HRT. The presence of 5-CHMS was not observed in the effluent at higher HRT. However, further decrease in HRT to $18 \mathrm{~h}$ leads to drastic decrease in biodegradation rate to $50 \%$. At $18 \mathrm{~h}$ HRT, biomass concentration in the bioreactor medium was suddenly decreased as washout occurs and biomass growth rate was decreased. Also, the bioreactor medium has been found to turn into light brown color and 4-CP concentration in the effluent increases suddenly. Effect of different HRT on the volumetric removal rate of 4-CP $(400 \mathrm{mg} / \mathrm{L})$ is shown in Fig. 4. The HRT was again

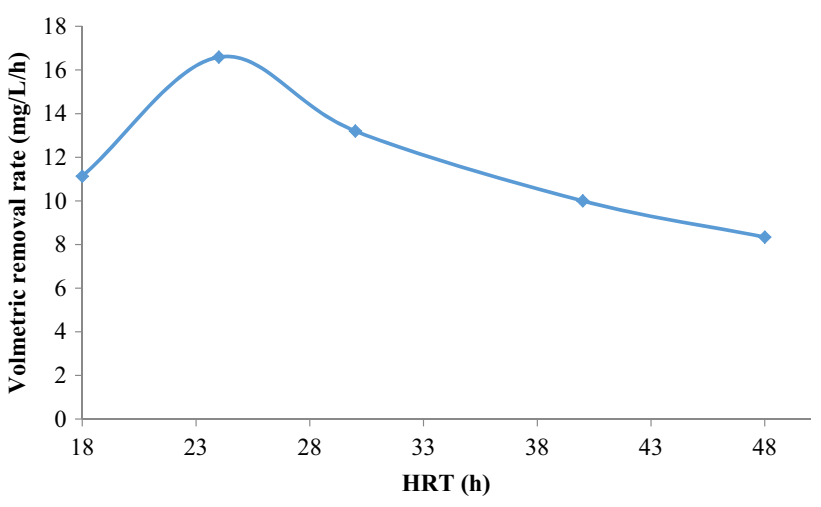

Fig. 4 Effect of HRT on the volumetric removal rate of 4-CP $(400 \mathrm{mg} / \mathrm{L})$ in the ALR with $0.2 \mathrm{~g} / \mathrm{L}$ of peptone

increased stepwise to 24 and $30 \mathrm{~h}$ to regain the biodegradation capacity of the reactor. The bioreactor takes some time to recover full degradation efficiency. At $24 \mathrm{~h}$ HRT, there was a slight increase in biodegradation rate observed. The biodegradation rate was gradually increased to $66 \%$ at steady state when HRT was increased to $30 \mathrm{~h}$. With time and increase in HRT, the bioreactor had showed to regain biodegradation capacity once again. Table 2 summarizes the change in volumetric removal rate with HRT and initial substrate concentration.

The relationship between volumetric loading rate and volumetric removal rate is depicted in Fig. 5. The removal rate was increased exponentially with loading rate up to $16.67 \mathrm{mg} / \mathrm{L} / \mathrm{h}$, where $16.59 \mathrm{mg} / \mathrm{L} / \mathrm{h}$ volumetric removal rate was observed. However, when loading rate was increased to $22.25 \mathrm{mg} / \mathrm{L} / \mathrm{h}$, there was a drastic reduction in volumetric removal rate observed as shown in Fig. 5. So, for achieving maximum or greater than $98 \%$ removal rate, the HRT should be kept at $24 \mathrm{~h}$ and loading rate at $16.67 \mathrm{mg} / \mathrm{L} / \mathrm{h}$. Kargi and konya (2007) studied the effect of HRT on the removal of 4-CP in activated sludge unit. They have reported volumetric removal rate in the range of 360-720 mg/L/day with high COD for different HRT of $5-15 \mathrm{~h}$. After $15 \mathrm{~h}$ of HRT, there was no significant increase in the removal rate observed (Kargi and Konya 2007). In another study, it was reported that degradation of 4-CP was decreased with a decrease in HRT in UASB. The UASB had shown 90.1, 88.3, 84.6, and $83 \%$ degradation of 4-CP at 16, 12, 8, and $6 \mathrm{~h}$, respectively (Majumder and Gupta 2008). Table 3 shows the performance of different bioreactors for removal of chlorophenols where most of the studies had shown the removal of 4-CP below $200 \mathrm{mg} / \mathrm{L}$ of loading rate. Kargi and Konya (2007) had shown the removal of 4-CP up to $800 \mathrm{mg} / \mathrm{L}$ of loading rate with $90 \%$ efficiency (Kargi and Konya 2007). In the present study, the bioreactor had achieved $99.8 \%$ removal for higher loading rate of $400 \mathrm{mg} / \mathrm{L} / \mathrm{day}$. The performance of the 
Table 2 Removal of $4-\mathrm{CP}$ by ALR in the presence of $0.2 \mathrm{~g} / \mathrm{L}$ peptone

\begin{tabular}{lllllc}
\hline Time (day) & $\begin{array}{l}\text { Influent concentration } \\
(\mathrm{mg} / \mathrm{L})\end{array}$ & HRT $\pm 1(\mathrm{~h})$ & $\begin{array}{l}\text { Loading rate } \\
(\mathrm{mg} / \mathrm{L} / \mathrm{day})\end{array}$ & $\begin{array}{l}\text { Biodegradation } \\
(\%)\end{array}$ & $\begin{array}{l}\text { Volumetric removal } \\
\text { rate }(\mathrm{mg} / \mathrm{L} / \mathrm{h})\end{array}$ \\
\hline 45 & 300 & 48 & 150 & 99 & 6.19 \\
$46-47$ & 400 & 48 & 200 & 100 & 8.34 \\
48 & 400 & 40 & 240 & 100 & 10 \\
49 & 400 & 30 & 320 & 99 & 13.2 \\
$50-52$ & 400 & 24 & 400 & 99.5 & 16.59 \\
$53-56$ & 400 & 18 & 534 & 50 & 11.13 \\
\hline
\end{tabular}

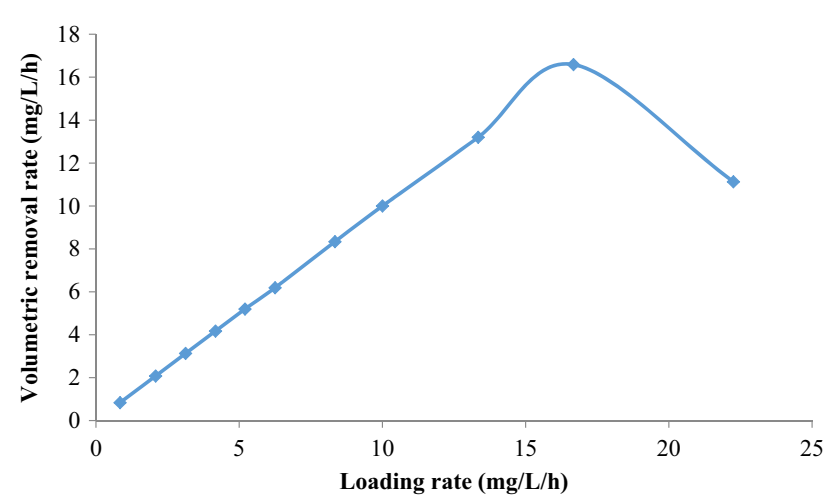

Fig. 5 Effect of loading rate on the volumetric removal of 4-CP in the ALR with $0.2 \mathrm{~g} / \mathrm{L}$ of peptone

ALR for removal of 4-CP is prominent and can successfully applied for contaminated wastewater treatment.

\section{Metabolites}

During the biodegradation of 4-CP by airlift inner loop reactor, the spectroscopic and HPLC analysis indicates the presence of 5-CHMS in the effluent. At lower 4-CP concentration, no metabolites had been detected in the effluent. However, at higher 4-CP concentration, the presence of
5-CHMS $\left(\lambda_{\max }=380 \mathrm{~nm}\right)$ was detected. This was also evidenced by the appearance of light yellow color in the reactor medium. 5-CHMS is the meta-cleavage product of the 4-chlorocatechol, the first intermediate of the 4-CP degradation pathway. When 4-CP concentration is above $300 \mathrm{mg} / \mathrm{L}$, the calorimetric assay of the effluent sample shows the presence of 4-chlorocatechol. The presence of metabolites showed that the mixed consortium follows the meta-cleavage pathway for 4-CP biodegradation. There were no other metabolites detected in the effluent. These results were also confirmed in the batch study. The degradation of 4-CP via meta-cleavage pathway by the mixed consortium has been reported (Farrell and Quilty 1999; El-Sayed et al. 2009).

Single bacterial strain can degrade toxic compounds completely if provided the feasible environment and presence of primary growth substrate. However, sometimes pure strain does not possess or express all the enzymes required for complete mineralization of toxic compounds. They specifically express the enzymes that act on parent compounds and produce the intermediate metabolites. These intermediate metabolites remain in the medium unutilized, because the lack of enzymes requires in the metabolic pathway. Also, application of pure strains for in situ environment is impractical as the dominance of

Table 3 Biodegradation of chlorophenols using different bioreactors

\begin{tabular}{lllllll}
\hline Bioreactor & Compound & $\begin{array}{l}\text { Concentration } \\
(\mathrm{mg} / \mathrm{L})\end{array}$ & HRT $(\mathrm{h})$ & $\begin{array}{l}\text { Loading rate } \\
(\mathrm{mg} / \mathrm{L} / \mathrm{day})\end{array}$ & $\begin{array}{l}\text { Removal } \\
\text { rate }(\%)\end{array}$ & References \\
\hline FBR & $4-\mathrm{CP}$ & 99.13 & 24.4 & 97.5 & 98.7 & Galíndez-Mayer et al. (2008) \\
PBR & $4-\mathrm{CP}$ & 20 & 2.78 & 172 & 100 & Kim et al. (2002) \\
CSTR & $4-\mathrm{CP}$ & 20 & 4.17 & 115 & 100 & Kim et al. (2002) \\
UASB & $4-\mathrm{CP}$ & 40 & 12 & 80 & 88.3 & Majumder and Gupta (2008) \\
ASU & $4-\mathrm{CP}$ & 500 & 15 & 800 & 90 & Kargi and Konya (2007) \\
ALR & 2,4-DCP & $7-103$ & 6.25 & $26-394$ & $100-88$ & Quan et al. (2003) \\
ALR & $2,4-D C P$ & 28.5 & 8 & 85.5 & 97.8 & Quan et al. (2004) \\
PB-ALR & 2,4,6-TCP & 5.76 & 2.95 & 46.88 & 99.9 & Gomez-De Jesus et al. (2009) \\
ALR & $4-\mathrm{CP}$ & 400 & 24 & 400 & 99.8 & This study
\end{tabular}

Activated sludge unit consisted of an aeration tank and a sludge settling tank (ASU); fluidized bed reactor (FBR); Packed bed reactor (PBR); continuous stirred tank reactor (CSTR); upflow anaerobic sludge blanket (UASB); airlift reactor (ALR); Packed bed airlift reactor (PB-ALR) 
other strains over the special strains that are better fitted for the degradation of target compound. In nature or engineered system, microbial communities are responsible for the complete mineralization of the toxic compounds. The several species present act together in a coordinated way within the microbial community that leads to complete degradation of recalcitrant compounds. Also, mixed microbial consortium does not require the presence of other primary growth substrate such as phenol or carbon source for complete degradation or induction of enzymes for the transformation of target toxic compound. A better understanding of the role that microorganisms play in the biodegradation and removal of chlorophenol compounds from the environment could facilitate further research for effective implementation of bioremediation technologies for the contaminated sites. Specific treatment proficiency can enable removal of chlorophenols from the environment and subsequently their ecotoxicological effects.

\section{Conclusions}

An airlift bioreactor was evaluated for the removal of 4-chlorophenol in synthetic wastewater using the mixed microbial consortium isolated from the dye industries. The results demonstrated that different parameters such as hydraulic retention time, initial substrate concentration, and peptone as biogenic substrate have profound effect on 4-CP removal efficiency. The bioreactor showed an excellent removal efficiency for 4-CP throughout the operation with greater than $98 \%$ removal. The optimum hydraulic retention time for the bioreactor was found to be $24 \mathrm{~h}$ and below that the washout of the microbes observed. Effect of peptone showed that lower peptone concentration increases the removal efficiency; however, some peptone is necessary to maintain 4-CP removal efficiency. The maximum initial substrate concentration of $400 \mathrm{mg} / \mathrm{L}$ of 4-CP was efficiently removed up to $99 \%$ at $24 \mathrm{~h} \mathrm{HRT}$ and $0.2 \mathrm{~g} / \mathrm{L}$ peptone. The presence of 5-CHMS at a higher 4-CP concentration in the bioreactor establishes that the mixed consortium follows the metacleavage pathway. The stability and efficiency showed by the mixed consortium for different operating conditions indicate its suitability for in situ bioremediation over a pure strain.

Acknowledgments This research was supported by Department of Chemical Engineering, National Institute of Technology Rourkela.

\section{Compliance with ethical standards}

Conflict of interest The authors declare that they do not have any conflict of interest and the manuscript has been prepared by the consent of co-authors.
Open Access This article is distributed under the terms of the Creative Commons Attribution 4.0 International License (http:// creativecommons.org/licenses/by/4.0/), which permits unrestricted use, distribution, and reproduction in any medium, provided you give appropriate credit to the original author(s) and the source, provide a link to the Creative Commons license, and indicate if changes were made.

\section{References}

Alexander M (1999) Biodegradation and bioremediation. Academic, San Diego

Arnow LE (1937) colorimetric determination of the components of 3,4-dihydroxyphenylalaninetyrosine mixtures. J Biol Chem 118(2):531-537

Arora P, Bae H (2014) Bacterial degradation of chlorophenols and their derivatives. Microb Cell Fact 13(1):31

ATSDR (2015) Comprehensive environmental response, compensation, and liability act (CERCLA), priority list of hazardous substances

Atuanya EI, Chakrabarti T (2004) Kinetics of biotransformation of 2,4-dichlorophenol using UASB-reactor. Environ Monit Assess 96(1-3):129-141

Basak B, Bhunia B, Dutta S, Chakraborty S, Dey A (2013) Kinetics of phenol biodegradation at high concentration by a metabolically versatile isolated yeast Candida tropicalis PHB5. Environ Sci Pollut Res 21(2):1444-1454. doi:10.1007/s11356-013-2040-z

Basak B, Bhunia B, Dey A (2014) Studies on the potential use of sugarcane bagasse as carrier matrix for immobilization of Candida tropicalis PHB5 for phenol biodegradation. Int Biodeterior Biodegrad 93:107-117. doi:10.1016/j.ibiod.2014.05.012

Chakraborty S, Basak B, Dutta S, Bhunia B, Dey A (2013) Decolorization and biodegradation of congo red dye by a novel white rot fungus Alternaria alternata CMERI F6. Biores Technol 147:662-666. doi:10.1016/j.biortech.2013.08.117

Daniel V, Huber W, Bauer K, Suesal C, Mytilineos J, Melk A, Conradt C, Opelz G (2001) Association of elevated blood levels of pentachlorophenol (PCP) with cellular and humoral immunodeficiencies. Arch Environ Health 56(1):77-83. doi:10.1080/ 00039890109604057

Durruty I, Okada E, González J, Murialdo S (2011) Multisubstrate monod kinetic model for simultaneous degradation of chlorophenol mixtures. Biotechnol Bioproc Eng 16(5):908-915. doi:10. 1007/s12257-010-0418-Z

El-Sayed WS, Ismaeil M, El-Beih F (2009) Isolation of 4-chlorophenol-degrading bacteria, Bacillus subtilis OS1 and Alcaligenes sp. OS2 from petroleum oil-contaminated soil and characterization of its catabolic pathway. Aust J Basic Appl Sci 3(2):776-789

Farrell A, Quilty B (1999) Degradation of mono-chlorophenols by a mixed microbial community via a meta-cleavage pathway. Biodegradation 10(5):353-362

Field J, Sierra-Alvarez R (2008) Microbial degradation of chlorinated phenols. Rev Environ Sci Bio/Technol 7(3):211-241. doi:10. 1007/s11157-007-9124-5

Galíndez-Mayer J, Ramón-Gallegos J, Ruiz-Ordaz N, Juárez-Ramírez C, Salmerón-Alcocer A, Poggi-Varaldo HM (2008) Phenol and 4-chlorophenol biodegradation by yeast Candida tropicalis in a fluidized bed reactor. Biochem Eng J 38(2):147-157. doi:10. 1016/j.bej.2007.06.011

Gomez-De Jesus A, Romano-Baez FJ, Leyva-Amezcua L, JuarezRamirez C, Ruiz-Ordaz N, Galindez-Mayer J (2009) Biodegradation of 2,4,6-trichlorophenol in a packed-bed biofilm reactor equipped with an internal net draft tube riser for aeration and 
liquid circulation. J Hazard Mater 161(2-3):1140-1149. doi:10. 1016/j.jhazmat.2008.04.077

Herrera Y, Okoh A, Alvarez L, Robledo N, Trejo-Hernández M (2008) Biodegradation of 2,4-dichlorophenol by a Bacillus consortium. World J Microbiol Biotechnol 24(1):55-60. doi:10.1007/s11274-007-9437-0

Hollender J, Hopp J, Dott W (1997) Degradation of 4-chlorophenol via the meta cleavage pathway by Comamonas testosteroni JH5. Appl Environ Microbiol 63(11):4567-4572

Hu Z, Ferraina RA, Ericson JF, Smets BF (2005) Effect of long-term exposure, biogenic substrate presence, and electron acceptor conditions on the biodegradation of multiple substituted benzoates and phenolates. Water Res 39(15):3501-3510. doi:10. 1016/j.watres.2005.06.009

IARC (1986) IARC monographs on the evaluation of the carcinogenic risk of chemicals to humans: some halogenated hydrocarbons and pesticide exposures, vol 41. International agency for research on cancer, Lyon

Kargi F, Konya I (2007) Para-chlorophenol containing synthetic wastewater treatment in an activated sludge unit: effects of hydraulic residence time. J Environ Manage 84(1):20-26. doi:10.1016/j.jenvman.2006.04.002

Karn SK, Chakrabarty SK, Reddy MS (2010) Pentachlorophenol degradation by Pseudomonas stutzeri CL7 in the secondary sludge of pulp and paper mill. J Environ Sci (China) 22(10): 1608-1612

Kim J-H, Oh K-K, Lee S-T, Kim S-W, Hong S-I (2002) Biodegradation of phenol and chlorophenols with defined mixed culture in shake-flasks and a packed bed reactor. Process Biochem 37(12):1367-1373. doi:10.1016/S0032-9592(02)00007-9

Majumder PS, Gupta SK (2008) Degradation of 4-chlorophenol in UASB reactor under methanogenic conditions. Bioresour Technol 99(10):4169-4177. doi:10.1016/j.biortech.2007.08.062

Monsalvo VM, Tobajas M, Mohedano AF, Rodriguez JJ (2012) Intensification of sequencing batch reactors by cometabolism and bioaugmentation with Pseudomonas putida for the biodegradation of 4-chlorophenol. J Chem Technol Biotechnol 87(9):1270-1275. doi:10.1002/jctb.3777

Murialdo SE, Fenoglio R, Haure PM, Gonzalez JF (2003) Degradation of phenol and chlorophenols by mixed and pure cultures. Water SA 29(4):457-463

Olaniran A, Igbinosa E (2011) Chlorophenols and other related derivatives of environmental concern: properties, distribution and microbial degradation processes. Chemosphere 83:1297-1306

Patel BP, Kumar A (2015) Optimization study for maximizing 2,4dichlorophenol degradation by Kocuria rhizophila strain using response surface methodology and kinetic study. Desalin Water Treat. doi:10.1080/19443994.2015.1091988

Patel BP, Kumar A (2016) Biodegradation of 2,4-dichlorophenol by Bacillus endophyticus strain: optimization of experimental parameters using response surface methodology and kinetic study. Desalin Water Treat 57(34):15932-15940. doi:10.1080/ 19443994.2015.1076351

Poggi-Varaldo HM, Barcenas-Torres JD, Moreno-Medina CU, Garcia-Mena J, Garibay-Orijel C, Rios-Leal E, Rinderknecht-Seijas $N$ (2012) Influence of discontinuing feeding degradable cosubstrate on the performance of a fluidized bed bioreactor treating a mixture of trichlorophenol and phenol. J Environ Manage 113:527-537. doi:10.1016/j.jenvman.2012.03.015

Quan X, Hanchang S, Yongming Z, Jianlong W, Yi Q (2003) Biodegradation of 2,4-dichlorophenol in an air-lift honeycomblike ceramic reactor. Process Biochem 38(11):1545-1551. doi:10.1016/S0032-9592(03)00046-3

Quan X, Shi H, Zhang Y, Wang J, Qian Y (2004) Biodegradation of 2,4-dichlorophenol and phenol in an airlift inner-loop bioreactor immobilized with Achromobacter sp. Sep Purif Technol 34(1-3):97-103. doi:10.1016/S1383-5866(03)00181-3

Sahinkaya E, Dilek FB (2006) Effect of biogenic substrate concentration on 4-chlorophenol degradation kinetics in sequencing batch reactors with instantaneous feed. J Hazard Mater 137(1):282-287. doi:10.1016/j.jhazmat.2006.01.069

Sahinkaya E, Dilek FB (2007) Effect of feeding time on the performance of a sequencing batch reactor treating a mixture of 4-CP and 2,4-DCP. J Environ Manage 83(4):427-436. doi:10. 1016/j.jenvman.2006.04.007

Shen DS, Liu XW, Feng HJ (2005) Effect of easily degradable substrate on anaerobic degradation of pentachlorophenol in an upflow anaerobic sludge blanket (UASB) reactor. J Hazard Mater 119(1-3):239-243. doi:10.1016/j.jhazmat.2004.12.024

Visvanathan C, Thu LN, Jegatheesan V, Anotai J (2005) Biodegradation of pentachlorophenol in a membrane bioreactor. Desalination 183(1-3):455-464. doi:10.1016/j.desal.2005.03.046

Wang S-J, Loh K-C (1999) Facilitation of cometabolic degradation of 4-chlorophenol using glucose as an added growth substrate. Biodegradation 10(4):261-269. doi:10.1023/a:1008347630546

Wang Q, Li Y, Li J, Wang Y, Wang C, Wang P (2014) Experimental and kinetic study on the cometabolic biodegradation of phenol and 4-chlorophenol by psychrotrophic Pseudomonas putida LY1. Environ Sci Pollut Res. doi:10.1007/s11356-014-3374-x

Ziagova M, Liakopoulou-Kyriakides M (2007) Kinetics of 2,4dichlorophenol and 4-Cl-m-cresol degradation by Pseudomonas sp. cultures in the presence of glucose. Chemosphere 68(5):921-927. doi:10.1016/j.chemosphere.2007.01.039

Zilouei H, Guieysse B, Mattiasson B (2006) Biological degradation of chlorophenols in packed-bed bioreactors using mixed bacterial consortia. Process Biochem 41(5):1083-1089. doi:10.1016/j. procbio.2005.11.019 